\title{
Clinical management of chronic atopic dermatitis in a goat: a case report
}

\begin{abstract}
A 4 years old Jamnapari cross buck weighing $50 \mathrm{~kg}$ was presented to the Veterinary Teaching Hospital, Universiti Putra Malaysia, with a primary complaint of dry crusty and alopecic skin lesions on the ventral neck, thoracic, abdominal, scrotal, perianal, and interdigital regions. The animal was physically sound with normal appetite and was managed intensively for breeding purposes. Hematological analysis showed a marked leucocytosis characterized by eosinophilia and netrophilia with degenerative left shift. Skin scrappings taken showed no ectoparasites and the vital parameters were within the normal range. Other systems appeared normal except the integumentary system which showed crusty and alopecic skin lesions on different parts of the body. The case was first tentatively diagnosed as dermatitis and effectively managed following a gradual change of feed and the administration of a single intradermal injection of $50 \mathrm{mg}(10 \mathrm{mg} / \mathrm{kg})$ chlorpheniramine maleate, $50 \mathrm{mg}$ of long acting oxytetracycline hydroxide $(20 \mathrm{mg} / \mathrm{kg}$, I.M) repeated four days later and multivitamin injection, $10 \mathrm{mg} / \mathrm{kg}$ for five days. This report highlights the significance of atopic dermatitis among goats and the need for its early and effective management in breeder farms and to provide a simple systematic approach for veterinarians and animal scientists in diagnosing and managing the condition.
\end{abstract}

Keyword: Management; Chronic; Atopic dermatitis; Goat 